\title{
Original
}

\section{Elimination of False Positive Signals for von Willebrand Factor mRNA Detected by Reverse Transcription/PCR Methods Required an Oligonucleotide Probe Distinct from the PCR Primer Sequences : An Example of a Common Avoidable Pitfall of PCR Technique}

\author{
Masahiko YAmaGuchi ${ }^{1)}$, Kaoru Kumada ${ }^{1)}$, Elaine Y. LeE ${ }^{2)}$ \\ and John B. SHAREFKIN ${ }^{2)}$
}

\begin{abstract}
Detection of specific mRNA signals using reverse transcription linked with polymerase chain reactions $(\mathrm{RT} / \mathrm{PCR})$ requires a minimum of two oligonucleotides used as sense and antisense primers for PCR. Identification of the resultant RT/PCR products is usually accomplished by either verifying digestion into the correct fragment sizes from a predicted restriction site internal to the amplified sequence or by hybridization using an oligonucleotide probe complementary to a portion of the amplified product.

In this report we describe an instance in which RT/PCR of mRNA from cell lines (human fibroblasts and vascular smooth muscle), which did not express a given gene (von Willebrand factor), led to spurious amplification of cDNA products that appeared to have the correct predicted size on agarose gel electrophoresis and that also gave positive hybridization to probes made from PCR primers used for amplification. Cell lines (human endothelial cells) that did express the gene, however, gave positive hybridization signals for a probe complementary to a third region internal to the amplified sequence. This probe did not show any false hybridization to the amplified DNA products from fibroblasts and smooth muscle cells. This example indicates that three determinants (sense and antisense primers and predicted product size) are not enough to identify a true mRNA signal by RT/PCR. A fourth determinant, such as an oligonucleotide probe, needs to be employed to definitively identify RT/PCR amplification products.
\end{abstract}

Key words : endothelial cells, polymerase chain reaction, reverse transcription, smooth muscle cells, von Willebrand factor

\section{Introduction}

von Willebrand factor ( $v W F$ ) is a large multimeric glycoprotein that contributes to platelet adhesion and formation of a platelet plug during blood vessel injury and binds to and stabilizes factor VIII in the circulation. vWF is synthesized only by endothelial cells

\footnotetext{
1) Department of Surgery, Showa University Fugigaoka Hospital, 1-30, Fugigaoka, Aoba-ku, Yokohama 227-8501, Japan.

2) New England Medical Center Hospitals, Boston, Massachusetts, USA.
} 
(ECs) and megakaryocytes ${ }^{1)}$, and is, therefore, used as a marker to differentiate EC from smooth muscle cells (SMCs) and fibroblasts by immunohistological staining. In this report, we describe a polymerase chain reaction (PCR) primer set for amplification of reverse transcribed mRNA for VWF whose use in a reverse transcription (RT)/PCR protocol led to amplification of false positive amplified products from the mRNA of SMCs and fibroblasts which had the same sizes as those from ECs when studied with agarose gel electrophoresis. Furthermore, these false positive bands generated from SMC and fibroblast RNA showed hybridization to the primers used for the PCR. Only the use of a third oligonucleotide probe sequence sited between the PCR primers led to unequivocally negative hybridization signals for SMCs and fibroblasts and a positive signal for ECs. These results show the need to employ a third oligonucleotide probe internal to the amplified PCR product for definitive identification of amplified products from RT/PCR reactions.

\section{Material and Methods}

Cell cultures: Human ECs were enzymatically harvested from saphenous vein segments discarded after coronary bypass operations ${ }^{2)}$. Human SMCs were obtained by outgrowth from explants taken from the media of the same vein segments after EC harvest was performed $^{3)}$. Human skin fibroblasts were a generous gift from Dr. M. Yaar (Dept. of Dermatology, New England Medical Center Hospitals, Boston, MA). The identity of EC cultures grown using EC growth factors was verified both by their cobblestone monolayer appearance and by immunohistologic staining using a polyclonal rabbit antiserum against human vWF incorporated in a staining kit (Endo-Rap Kit, Endo-Tech Corp., Indianapolis, IN). ECs were passaged at 1:6 ratios when confluent and studied in third passage. The identity of SMC cultures was verified by their characteristic hill and valley morphology and by positive immunohistologic staining for SMC-specific actin isotypes using the monoclonal antibody HHF354). SMCs were studied when confluent in passages threeto five.

Oligonucleotide primers and probe: Sense and antisense primers for human vWF and an oligonucleotide probe for a region lying between the primers were selected by the rules incorporated in a computer program for PCR primer optimization previously described by us $^{5)}$ uging a published complete cDNA sequence for human $\mathrm{VWF}^{6)}$ (Table I). Sense and antisense vWF primers were positioned in different exons, namely exons 21 (sense primer, $\mathrm{Tm}: 60^{\circ} \mathrm{C}$ ) and 23 (antisense primer, $\mathrm{Tm}: 60^{\circ} \mathrm{C}^{8)}$ to prevent any spurious amplification of vWF genomic DNA contaminating the RNA preparation. The 308-base pair (bp)-long cDNA segment amplified by this set of PCR primers was located in a part of the reading frame corresponding to the D3 domain that is not involved in the type A domain superfamily ${ }^{9)}$. An oligonucleotide probe sequence was selected from exon 22 to lie in a site between the sense and antisense primers. To check accidental homologies of these primers and the probe to non-vWF sequences, a homology search was done against all mammalian sequences in GenBank (Ver.4, Fall 1990, NBRF release 25). The search was done with Microgenie $^{\mathrm{TM}}$ software (Beckman lnc., Fullerton, CA) at a stringency level of only detecting matches of 12 or more base pairs per primer to non-vWF sequences. No matches were found with estimated annealing temperatures of $50{ }^{\circ} \mathrm{C}$ or greater, whereas all experiments were done with PCR cycle annealing temperatures of $55^{\circ} \mathrm{C}$.

To verify that $\mathrm{RT} / \mathrm{PCR}$ reactions did not fail in the enzymatic reactions, parallel RT/PCR reactions were done for all RNA samples to detect mRNA for the constitutively 
Table 1. Oligonucleotide primers and probes used for reverse transcription, polymerase chain reaction, and detection by Southern hybridization of amplified products for human von Willebrand factor ( $v W F$ ) and glyceraldehyde-3-phosphate dehydrogenase (GAPDH).

Base pair positions are those given in the original published cDNA sequence for human vWF (Bonthron, et al. 1986) ${ }^{6}$ and GAPDH (Arcari et al. 1984) ${ }^{71}$. Predicted size for the amplified product was 308 bp for vWF and 195 bp for GAPDH.

\begin{tabular}{llll}
\hline Gene & Oligonucleotide & \multicolumn{1}{c}{ Sequence } & Position \\
& Sense primer & 5'-GATCCTAGTGGGGAATAAGG-3' & $2817-2836$ \\
vWF & Antisense primer & 5'-TGGTGAGGTCATTGTTCTGG-3' & $3124-3105$ \\
& Probe & 5'-CCCATGAAGGATGAGACTCACT-3' $^{\prime}$ & $2935-2956$ \\
& Sense primer & 5'-CCATGGAGAAGGCTGGGG-3' $^{\prime}$ & $371-388$ \\
GAPDH & Antisense primer & 5'-CAAAGTTGTCATGGATGACC-3' & $565-546$ \\
& Probe & 5'-CTAAGCAGTTGGTGGTGCA-3' & $532-514$ \\
\hline
\end{tabular}

expressed control gene for glyceraldehyde-3-phosphate dehydrogenase (GAPDH) using a primer and probe set previously described ${ }^{10)}$ (Table I).

RT/PCR : Total cellular RNA was extracted from cultures of EC, SMC, or Fb using the guanidinium-phenol-chloroform method of Chomczynski and Sacchi ${ }^{11)}$. All reagents were made RNase free by either double filtration through $0.2-\mu \mathrm{m}$ nitrocellulose filters (MILLEXGS, Millipore Co., Bedford, MA) or diethylpyrocarbonate treatment ${ }^{12)}$.

The RT of mRNA was done in a $25-\mu 1$ reaction volume containing $1 \mu \mathrm{g}$ of total cellular RNA, $500 \mathrm{U}$ MMLV RT enzyme (BRL/Gibco, Bethesda, MD), $0.5 \mu \mathrm{g}$ of antisense primer, all four deoxynucleotide phosphates (dNTPs : $0.5 \mathrm{mM}$ each) in RT buffer of $50 \mathrm{mM}$ Tris/ $\mathrm{HCl}$ ( $\mathrm{pH}: 8.3$ ), $75 \mathrm{mM} \mathrm{KCl}, 3 \mathrm{mM} \mathrm{MgCl}_{2}$ and $10 \mathrm{mM}$ dithiothreitol (DTT). An initial mixture of antisense primer, total RNA, and $\mathrm{H}_{2} \mathrm{O}$ was heated at $70{ }^{\circ} \mathrm{C}$ for 6 minutes and chilled on ice. Then a complete reaction mixture was made by adding $5 \mathrm{x}$ RT buffer, dNTPs, DTT, and RT enzyme and incubated at $37^{\circ} \mathrm{C}$ for 30 minutes. The RT reaction was then stopped by heating at $95{ }^{\circ} \mathrm{C}$ for 10 minutes. The cDNA products were amplified using PCR in a total volume of $100 \mu 1$ using $2 \mathrm{U}$ of recombinant Thermus Aquaticus (Taq) DNA polymerase (Perkin-Elmer Cetus, Norwalk, CT), $0.5 \mu \mathrm{g}$ of added sense primer, $0.25 \mu \mathrm{g}$ added antisense primer, and all four dNTPs $(0.625 \mathrm{mM}$ each) in PCR buffer of $22.5 \mathrm{mM}$ Tris $/ \mathrm{HCl}$ ( $\mathrm{pH}: 8.3$ ), $68.75 \mathrm{mM} \mathrm{KCl}, 3.25 \mathrm{mM} \mathrm{MgCl}_{2}$ in $0.01 \%$ gelatin. We performed the RT/PCR to detect vWF mRNA using 25 cycles PCR with a Perkin-ElmerCetus Thermal cycler with cycle setting of $94{ }^{\circ} \mathrm{C} \times 20$ seconds $60{ }^{\circ} \mathrm{C} \times 30$ seconds, and $72{ }^{\circ} \mathrm{C} \times 90$ seconds, and GAPDH mRNA using 20 cycles PCR with cycle setting of $94{ }^{\circ} \mathrm{C}$ $\times 20$ seconds, $58{ }^{\circ} \mathrm{C} \times 30$ seconds, and $72{ }^{\circ} \mathrm{C} \times 90$ seconds.

From each reaction, $12 \mu 1$ of PCR products were fractionated in a $2 \%$ agarose gel. Gels were stained with ethidium bromide, photographed under ultraviolet light denatured, neutralized, blotted overnight onto a nylon membrane (Nytran, schleicher \& Schuell, Keene, $\mathrm{NH}$ ), crosslinked with ultraviolet irradiation, and baked for 2 hours at $80{ }^{\circ} \mathrm{C}$. Blotted membranes were successively hybridized, stripped by boiling for 2 minutes in $10 \mathrm{mM}$ Tris/ $0.1 \%$ sodium dodecyl sulfate (SDS), and rehybridized using vWF sense primer, antisense primer, or the internally sited oligonucleotide probe labelled with ${ }^{32} \mathrm{P}$-ATP using T4 polynucleotide kinase, and washed in $0.1 \%$ SDS/5X SSPE $\left(\mathrm{NaCl}, \mathrm{Na}_{2} \mathrm{HPO}^{4}\right.$, EDTA) at $56{ }^{\circ} \mathrm{C}$ for a total of 1 hour in three wash steps. Using intensifying screens, Kodak type 
XRP X-ray films (Eastman Kodak, Rochester, NY) were exposed to hybridized membranes at- $70{ }^{\circ} \mathrm{C}$ for periods of 1 to 4 days.

\section{Results}

Stained gel photographs showed a band of amplified product at the predicted 308-bp size in the EC lane, but bands of this size were also present in the SMC and fibroblast lanes (Fig. 1 A). Autoradiographs of Southern blot hybridization employing a radiolabeled sense primer showed strong hybridization signals in ECs and very weak signals in SMCs and fibroblasts at the 308-bp level (Fig. 1 B). Southern blot hybridization using a radiolabeled antisense primer showed similar strong signals in the EC, SMC, and fibroblast lanes at 308-bp levels (Fig. 1 C). Autoradiographs of Southern blot hybridizations with the separate radiolabeled oligonucleotide probe sequence chosen to lie between the primers, ho wever, showed only one clear band of 308-bp size in the EC lane, and no signal was detected in the SMC and fibroblast lanes. Constitutively expressed GAPDH signals were detected by Southern blot hybridization using an oligonucleotide probe at similar strength in all (EC, SMC, and fibroblast) lanes (Fig. 2). These GAPDH results confirm that the RT/PCR in our protocol did not fail in enzymatic reactions and that all RNA samples were not degraded and were equally present in each reaction tube.

\section{Discussion}

We have shown that a sense and antisense primer set for vWF produces false positive amplified products from SMC and fibroblast RNA but that use of a separate oligonucleotide probe sited between the sense and antisense primers eliminates false positive signals and hybridizes only to amplified cDNA from EC. Considering the results of hybridization different when the sense or antisense oligonucleotide was used as a probe, we carried out additional RT/PCR reactions under the same conditions as for the described protocol without the sense primer. Stained gel photographs showed similar strength bands of amplified product at the same 308-bp size as Fig. $1 \mathrm{~A}$ in all three kinds of cells (Fig. 3 ).

On the basis of this result, we conclude that the false band products were made only by the antisense oligonucleotide and that the sequence of these products had the antisense primer sequence and sequences complementary to the antisense primer at both edges so that the sequence of false products are different from the intended one.

These findings suggest that RT/PCR methods sometimes can amplify false positive cDNA segments of the same base pair size predicted for the true positive cDNA PCR product. They also suggest that only one oligonucleotide primer can make certain base pair products that confuse the detection of the true signal by RT/PCR. As described in this paper, this situation arose in spite of a comptete homology search of the GenBank library that revealed no significant homology of non-vWF genes to our chosen primers. This fact underscores the principle that a separate oligonucleotide probe or other method, such as restriction di gest, is necessary to discriminate between such a false positive signal and a genuine signal from the intended target gene.

Hence, even if an $\mathrm{RT} / \mathrm{PCR}$ reaction leads to observation of a single band of correct predicted size on the gel, subsequent verification of the products, such as hybridization with a specific probe, is needed to definitively rule out a false positive signal. This point is notable because many studies have employed only the sense and antisense primers ${ }^{13-16)}$, 
A

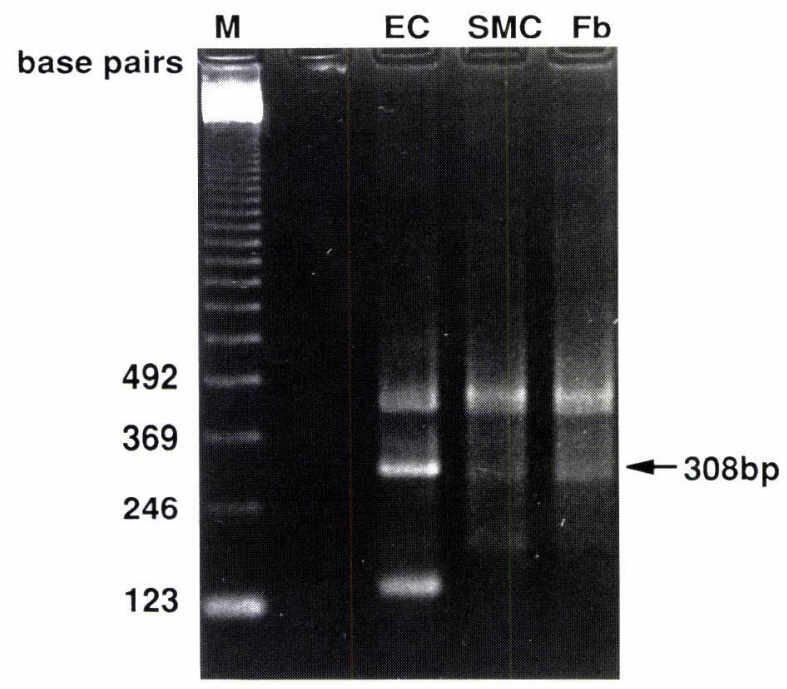

Fig. $1 \mathrm{~A}$.

B

\section{EC SMC Fb}

C

\section{$\mathrm{EC} \mathrm{SMC} \mathrm{Fb}$}
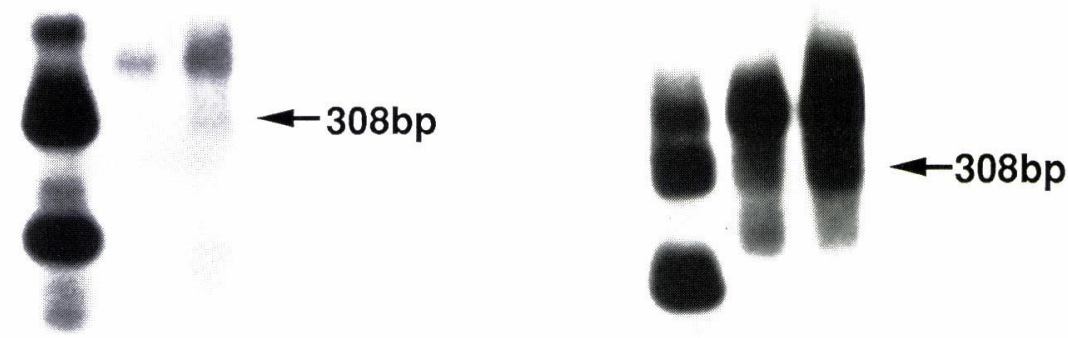

Fig. 1 B .

Fig. $1 \mathrm{C}$.

Fig. $1 \mathrm{~A}$. Ethidium bromide staining of RT/PCR products of $\mathrm{vWF}$ mRNA separated in $2 \%$ agarose gel showing clear band in EC lane and faint bands in SMC and fibroblast lanes at 308-bp length level. Lanes: M, 123 ladder molecular weight markers; EC, endothelial cell ; SMC, smooth muscle cell; $\mathrm{Fb}$, fibroblast.

Fig. 1 B. Autoradiograph of Southern blot of RT/PCR products hybridized with radiolabeled $v W F$ sense primer

Fig. $1 \mathrm{C}$. Autoradiograph of Southern blot of RT/PCR products hybridized with radiolabeled $\mathrm{vWF}$ antisense primer

although some of these studies effectively substitute restriction digest of the amplified product into correctly predicted fragment sizes for Southern hybridization to clearly identify the product ${ }^{17)}$. Some reports described a simpler and faster identification method employing liquid hybridization to PCR products with an internal oligonucleotide probe instead of Southern blot hybridization ${ }^{18)}$.

To achieve more specificity of amplification, we tried another primer set (sense primer 


\section{EC SMC $\mathrm{Fb}$}

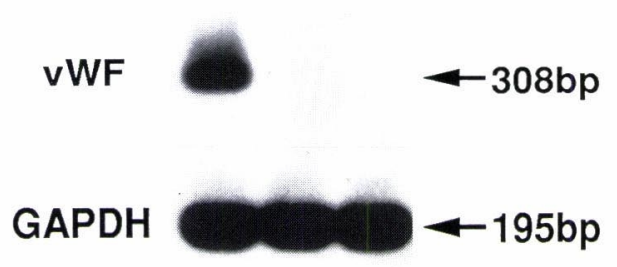

Fig. 2. Autoradiograph of Southern blot of RT/PCR products done to compare vWF and GAPDH mRNA signals in ECs, SMCs, and fibroblasts (Fb). Upper autoradiograph shows result of hybrydization with a probe whose sequence is internally located in the amplified 308-bp region of the vWF cDNA sequence; lower autoradiograph shows result of separate Southern blot of RT/PCR for GAPDH mRNA signal detection using a specific oligonucleotide probe.

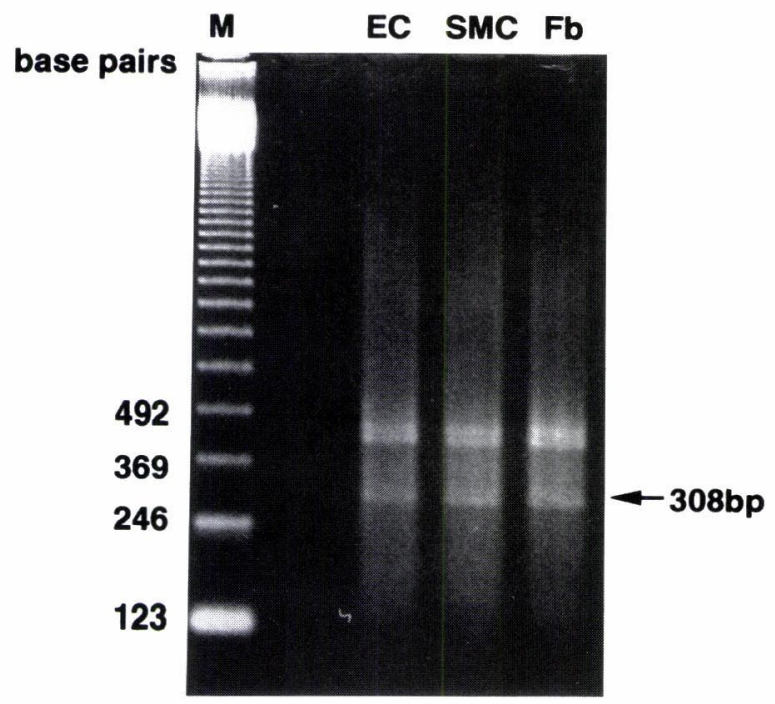

Fig. 3. Staining gel photo of the RT PCR products in $2 \%$ agarose gel showing the bands in EC, SMC, and fibroblast lanes at 308-bp length level. The RT/PCR reactions were carried out under the same conditions as for vWF mRNA detection but without the sense primer. Lanes: M, 123 ladder molecular weight markers; EC, endothelial cell; SMC, smooth muscle cell; $\mathrm{Fb}$, fibroblast.

position : 186-209 b in exon 10, antisense primer position : 257-280 b in exon 11 in human vWF gene from GenBank) for vWF mRNA signal detection. However, the amplification efficiency of RT/PCR was not as good as with our previous primer set. The false products we observed could have resulted from imperfect annealing of the sense and antisense primers to an unrelated mRNA sequence. In some cases the use of agents, such as dimethyl sulfoxide, formamide, or tetramethylammonium chloride (TMAC), has been reported to reduce such non specific annealing ${ }^{19,20)}$. However, in this case we could not diminish or eliminate the false positive bands even though we tested the use of formamide, TMAC, a 
higher annealing temperature of $62^{\circ} \mathrm{C}$, and various concentrations of $\mathrm{Mg}^{2+}(2.5,3.25,4.0$ $\mathrm{mM}$ ) in $\mathrm{RT}+\mathbf{P C R}$ reactions done with this primer set for $\mathrm{vWF}$ mRNA detection (data not shown).

\section{References}

1) Wagner DD : Cell biology of Von Willebrand factor. Annu Rev Cell Biol 6 : 217-246 (1990)

2) Sharefkin JB, Van Wart HE, Cruess DF, Albus RA and Levine EM: Adult human endothelial cell enzymatic harvesting: Estimates of efficiency and comparison of crude and partially purified bacterial collagenase preparations by replicate microwell culture and fibronectin degradation measured by enzyme-linked immunosorbent assay. J Vasc Surg 4 : 567-577 (1986)

3) Yamaguchi M, Du W, Gould KE, Dieffenbach CW, Cruess DF and Sharefkin JB : Effects of aspirin, dipyridamole, and dibutyryl cyclic adenosine monophosphate on platelet-derived growth factor A chain mRNA levels in human sap henous vein endothelial cells and smooth muscle cells. Surgery 110 : 377-384 (1991)

4) Tsukada T, Tippens D, Gordon D, Ross Rand Gown AM: HHF35, a muscle-actin-specific monoclonal antibody. I. Immunocytochemical and biochemical characterization. Am J Pathol 126: 51-60 (1987)

5) Lowe T, Sharefkin JB, Yang $\mathrm{S}$ and Dieffenbach $\mathrm{CW}: \mathrm{A}$ computer program for selection of oligonucleotide primers for polymerase chain reactions. Nucl Acids Res 18 : 1757-1761 (1990)

6) Bonthron D, Orr EC, Mitsock LM, Ginsburg D, Handin Rl and Orkin SH : Nucleotide sequence of pre-pro-von Willebrand factor cDNA. Nucl Acids Res 14 : 7125-7127 (1986)

7) Arcari P, Martinelli Rand Salvatore F: The complete sequence of a full length cDNA for human liver glyceraldehyde-3-phosphate dehydrogenase : evidence for multiple mRNA species. Nucl Acids Res 12 : 91799189 (1984)

8) Mancuso D J, Tuley EA, Westfied LA, Worrall NK, Shelton-Inloes BB, Sorace JM, Alevy JG and Sadler JE : Structure of the gene for human von Willebrand factor. J Biol Chem 264 : 19514-19527 (1989)

9) Verweij CL, Diergaarde PJ and Pannekoek H : Full-length von Willebrand factor (vWF) cDNA encodes a highly repetitive protein considerably larger than the mature vWF subunit. EMBO J 5 : 1839-1847 (1986)

10) Diamond SL, Sharefkin JB, Dieffenbach C, Frasier. Scott-K, Mclntire LV and Eskin SG: Tissue plasminogen activator messenger RNA levels increase in cultured human endothelial cells exposed to laminar shear stress. J Cell Physiol 143 : 364-371 (1990)

11) Chomczynski $\mathbf{P}$ and Sacchi $\mathbf{N}$ : Single-step method of RNA isolation by acid guanidinium thiocyanate-phenolchloroform extraction. Anal Biochem 162:156-159 (1987)

12) Ausubel FM, Brent R, Kingston RE, Moore DD, Seidman JG, Smith JA and Struhl K : Short Protocols in Molecular Biology. J. Wiley \& Sons, Inc., New YorK, (1989)

13) Wang AM, Doyle MV and Mark DF : Quantitation of mRNA by the polymerase chain reaction. Proc Natl Acad Sci USA 86 : 9797-9721 (1989)

14) Gilliland G, perrin S, Blanchard $K$ and Bunn HF : Analysis of cytokine mRNA and DNA : Detection and quantitation by competitive polymerase chain reaction. Proc Natl Acad Sci USA 87 : 2725-2729 (1990)

15) Singer-Sam J, Robinson MO, Bellve AR, Simon MI and Riggs AD : Measurement by quantitative PCR of changes in HPRT, PGK-1, PGK-2, APRT, MTase, and Zfy gene transcripts during mouse spermafogenesis. Nucl Acids Res 18 : 1255-1259 (1990)

16) Robinson MO and Simon MI. Determining transcript number using the polymerase chain reaction: Pgk-2, mP2, and PGK-2 transgene mRNA levels during spermatogenesis. Nucl Acids Res 19 : 1557-1562 (1991)

17) Rappolee DA, Mark D, Banda MJ and Werb Z: Wound macrophages express TGF- $\alpha$ and other growth factors in vivo: Analysis by mRNA phenotyping. Science 241: 708-712 (1988)

18) Kumar R, Goedert JJ and Hughes SH : A method for the rapid screening of human samples for the presence of HIV-1 sequences: the probe-shift assay. AIDS Res Hum Retroviruses 5 : 345-354 (1989)

19) Sarker G, Kapelner S and Sommer SS : Formamide can dramatically improve the specificity of PCR. Nucl Acids Res 18 : 7465 (1990)

20) Hung T, Mak K and Fong $\mathrm{K}: \mathrm{A}$ specificity enhancer for polymerase chain reaction. Nucl Acids Res $18: 4953$ (1990)

[ Received August 4, 1997 : Accepted October 1, 1997] 